OPEN ACCESS

Edited by: Geert Carmeliet, KU Leuven, Belgium

Reviewed by: Antonia Sophocleous, University of Edinburgh, United Kingdom

Beata Lecka-Czernik, University of Toledo, United States

*Correspondence: Marie Pereira m.pereira@imperial.ac.uk

Specialty section: This article was submitted to Bone Research, a section of the journal Frontiers in Endocrinology

Received: 09 August 2017 Accepted: 03 November 2017 Published: 20 November 2017

Citation:

Pereira M, Gohin S, Roux J-P, Fisher A, Cleasby ME, Mabilleau G and Chenu C (2017) Exenatide

Improves Bone Quality in a Murine Model of Genetically Inherited Type 2

Diabetes Mellitus.

Front. Endocrinol. 8:327. doi: 10.3389/fendo.2017.00327

\section{Exenatide Improves Bone Quality in a Murine Model of Genetically Inherited Type 2 Diabetes Mellitus}

\author{
Marie Pereira ${ }^{1 *}$, Stephanie Gohin ${ }^{1}$, Jean-Paul Roux ${ }^{2}$, Amy Fisher $^{3}$, Mark E. Cleasby', \\ Guillaume Mabilleau ${ }^{4}$ and Chantal Chenu ${ }^{1}$ \\ ${ }^{1}$ Department of Comparative Biomedical Sciences, Royal Veterinary College, London, United Kingdom, ${ }^{2}$ INSERM \\ UMR1033, Université de Lyon, Lyon, France, ${ }^{3}$ Transpharmation, London, United Kingdom, ${ }^{4}$ GEROM-LHEA UPRES EA \\ 4658, Institut de Biologie en Santé, Université d'Angers, Angers, France
}

Type 2 diabetes mellitus (T2DM) is associated with skeletal complications, including an increased risk of fractures. Reduced blood supply and bone strength may contribute to this skeletal fragility. We hypothesized that long-term administration of Exenatide, a glucagon-like peptide-1 receptor agonist, would improve bone architecture and strength of T2DM mice by increasing blood flow to bone, thereby stimulating bone formation. In this study, we used a model of obesity and severe T2DM, the leptin receptor-deficient $\mathrm{db} / \mathrm{db}$ mouse to assess alterations in bone quality and hindlimb blood flow and to examine the beneficial effects of 4 weeks administration of Exenatide. As expected, diabetic mice showed marked alterations in bone structure, remodeling and strength, and basal vascular tone compared with lean mice. Exenatide treatment improved trabecular bone mass and architecture by increasing bone formation rate, but only in diabetic mice. Although there was no effect on hindlimb perfusion at the end of this treatment, Exenatide administration acutely increased tibial blood flow. While Exenatide treatment did not restore the impaired bone strength, intrinsic properties of the matrix, such as collagen maturity, were improved. The effects of Exenatide on in vitro bone formation were further investigated in primary osteoblasts cultured under high-glucose conditions, showing that Exenatide reversed the impairment in bone formation induced by glucose. In conclusion, Exenatide improves trabecular bone mass by increasing bone formation and could protect against the development of skeletal complications associated with T2DM.

Keywords: exenatide, type 2 diabetes, db/db mice, skeleton, bone quality, blood flow

\section{INTRODUCTION}

Bone fragility is an important complication in patients with type 2 diabetes mellitus (T2DM), despite a normal or high-bone mineral density (BMD) (1), implying alterations of bone quality (2). The cellular and molecular mechanisms leading to the reduced bone strength and quality in T2DM patients are poorly characterized; but accumulation of advanced glycation end products, as a result of hyperglycemia and oxidative stress, changes in collagen cross-linking and suppression of bone turnover are thought to be significant contributors in the etiology of diabetic fractures $(3,4)$.

Glycemic control has been evidenced as a major intervention to reduce fracture in T2DM (5), suggesting that early lifestyle intervention and administration of anti-diabetic medications to reduce 
hyperglycemia are required. However, the choice of anti-diabetic medications is crucial as some anti-diabetic therapies can themselves result in increase in fracture risk by augmenting the risk of hypoglycemia and falls or by altering bone turnover and bone quality.

Incretin hormones, such as glucagon-like peptide-1 (GLP-1) and glucose-dependent insulinotropic peptide (GIP), are peptides secreted in the gastrointestinal tract that stimulate insulin secretion in response to the ingestion of nutrients in a glucosedependent manner and as such avoidance of hypoglycemia events (6). In opposition to GIP, GLP-1 resistance does not seem to occur in T2DM and as a result, GLP-1 receptor agonists (GLP-1RAs), including Exenatide, have been developed and marketed for the treatment of T2DM (6). A growing body of evidence suggest positive effects of GLP-1 or GLP-1RAs on bone physiology as demonstrated by rapid changes in gene expression or bone mass in several rodent models of ovariectomy-induced osteoporosis, genetically inherited or high-fat diet-induced T2DM (7-11). However, the possible effects of GLP-1RAs on bone quality that is compromised in T2DM, is still lacking. Based on evidences that Glp1r KO mice and GLP-1RA-treated osteoporotic mice, exhibit modifications of bone quality (12-14), we hypothesized that GLP-1RAs could improve bone quality in T2DM.

Furthermore, bone perfusion strongly correlates with metabolic activity and bone formation (15). This is dependent upon the number and size of blood vessels, which are regulated through the processes of angiogenesis and vasomotor function, respectively. Sufficient blood supply is crucial for bone formation, bone turnover, and fracture healing, poor blood supply being a major cause of impaired bone formation and delayed bone healing in the elderly and in osteoporosis $(16,17)$. T2DM is often associated with impaired vascular function (18) and a high risk of vascular disorders (19). Interestingly, it has been shown that administration of GLP-1RAs to T2DM patients attenuates hypertension, increases renal blood flow, and improves vascular endothelial function (20). Moreover, GLP-1R is expressed in endothelial and vascular smooth muscle cells (21), suggesting that GLP-1RAs may increase blood flow to bone, thereby stimulating bone formation.

The diabetic $\mathrm{db} / \mathrm{db}$ mouse is a widely used model of severe T2DM because of its shared features with human diabetes (22). These mice possess a mutation in the adipokine leptin receptor gene that causes obesity and subsequent spontaneous development of T2DM-like pathology, including early hyperlipidemia and hyperinsulinemia, followed by persistent hyperglycemia and decreased insulin secretion, as a result of pancreatic $\beta$-cell dysfunction (23). db/db mice exhibit skeletal fragility compared with their lean controls (22), in particular impaired trabecular and cortical microarchitectures and reduced bone strength due to poor bone quality $(22,24,25)$. Interestingly, an analog of the sister incretin hormone GIP has been shown to significantly improve bone quality and hence bone strength in the $\mathrm{db} / \mathrm{db}$ mice (25). In the shed of these results, it is clinically important to assess the effects of marketed GLP-1RAs on bone strength and quality in this rodent model.

The aims of the present study were to ascertain whether Exenatide can improve bone quality and strength in diabetic mice by studying bone microarchitectures, tissue material properties, cellular activities, and hindlimb blood flow in vivo. We also compared the effects of Exenatide on in vitro bone formation by osteoblasts cultured in low- and high-glucose environments.

\section{MATERIALS AND METHODS}

\section{Animals and Study Design}

Twenty male diabetic $(\mathrm{db} / \mathrm{db})$ mice (BKS.Cg-+Lepr ${ }^{\mathrm{db}} /+$ Lepr $^{\mathrm{db}} /$ OlaHsd) and 20 male lean mice (BKS.Cg-Dock7m+/+Leprdb/ OlaHsd) were purchased from Harlan Laboratories (Shardlow, UK) at 6 weeks of age and acclimatized to their housing $\left(21 \pm 1^{\circ} \mathrm{C}\right.$; $12 \mathrm{~h}$ day/night cycle) for 1 week. They were weighed and blood glucose measured at the end of each week using a glucometer (Accu-chek Aviva, Roche Diagnostics, UK). All mice were diabetic [blood glucose $>12 \mathrm{mmol} / \mathrm{L}(26)$ ] at 9 weeks of age. Then, both lean and $\mathrm{db} / \mathrm{db}$ mice were randomly allocated to treatment with saline (saline control and diabetic control) or $10 \mu \mathrm{g} / \mathrm{kg} /$ day Exenatide (Bachem, Switzerland) ( $n=10$ /group). Sample size calculations were based on previous work comparing Exenatide's effect to saline and $\mathrm{db} / \mathrm{db}$ mice to lean mice on the most relevant parameter for bone mass, the bone volume percentage (BV/TV) $(14,25)$ to achieve $80 \%$ power of detecting the difference with $5 \%$ of type 1 error rate.

Treatments were administered by daily subcutaneous injections for 4 weeks. At days 8 and 3 prior to euthanasia, mice were intraperitoneally injected with calcein $(20 \mathrm{mg} / \mathrm{kg})$ and alizarin red complexone (30 mg/kg) (Sigma, UK), respectively, to label bone-mineralizing surfaces. After necropsy, tibias and femurs were collected and cleaned of soft tissues. All animal procedures were approved by the institutional Ethics and Welfare committee and were carried out under UK Home Office license to comply with the Animals (Scientific Procedures) Act 1986 (PPL: 70/7859).

\section{Measurements of Whole Hindlimb Bone Perfusion in $\mathrm{db} / \mathrm{db}$ Mice}

Two days before blood flow measurement, the hair of the right hindlimb of $\mathrm{db} / \mathrm{db}$ mice was removed with a depilatory cream. Perfusion was measured in the right hindlimb using laser Doppler imaging (LDI) (MoorLDI2 Imager, Moor Instruments Ltd., UK). The animals were placed in the supine position during LDI measurement and the mean perfusion was estimated from the thigh to the foot to cover the tibia artery and vein. The distance between the camera and the hindlimb skin surface was $20 \mathrm{~cm}$.

To analyze the acute effects of Exenatide on hindlimb perfusion, mice were anesthetized using isofluorane, recordings were started $8 \mathrm{~min}$ before a subcutaneous injection of Exenatide (baseline) and continued during the following $30 \mathrm{~min}$. LDI measures the distribution of blood flux (combination of velocity and concentration of red blood cells) in arbitrary units for a selected region of interest $(19 \mathrm{~mm} \times 27 \mathrm{~mm})$ with a spatial resolution of $100 \mu \mathrm{m} /$ pixel. The estimated maximum depth of detectable vessels (in soft connective tissues) was $2-3 \mathrm{~mm}$ (laser wavelength $=830 \mathrm{~nm}$ ). LDI generates color-coded perfusion maps of larger tissue areas which allow the recording of precisely delimited regions of interest compatible for specific long bone perfusion measurements in mice (27). 


\section{Micro-CT Analysis of Tibiae}

Right tibiae were fixed in $4 \%$ formaldehyde for $48 \mathrm{~h}$ and stored in $70 \%$ ethanol at $4^{\circ} \mathrm{C}$. To analyze bone microarchitecture, trabecular and cortical compartments were scanned using high-resolution micro-computed tomography (Skyscan-1172/F Bruker, Belgium) operated at $55 \mathrm{kV}, 180 \mu \mathrm{A}, 1,710 \mathrm{~ms}$ integration time. The isotropic voxel size was fixed at $5 \mu \mathrm{m}$, the rotation step at $0.6^{\circ}$, and exposure was performed using a $0.5 \mathrm{~mm}$ aluminum filter. After scanning, whole tibiae were reconstructed using NRecon version 1.6.9.8 (Skyscan), trabecular and cortical bone areas were analyzed with CT-Analyser version 1.14.4.1 (Skyscan), and the quantification of bone structure was made using the analysis software Batman v.1.14.4.1. Trabecular parameters were assessed in the proximal metaphysis; $0.5 \mathrm{~mm}$ below the growth plate was left unanalyzed and the $2 \mathrm{~mm}$ following down was analyzed. These included: BV/ TV, trabecular thickness (Tb.Th), trabecular number (Tb.N), structure model index (SMI), trabecular bone pattern factor (Tb. Pf), and trabecular separation (Tb.Sp). Analysis of cortical bone in the midshaft diaphysis was performed using a $0.5 \mathrm{~mm}$ long segment at $50 \%$ of the total tibia length. Parameters consisted of: tissue area (Tt.Ar), tissue perimeter (Tt.Pm), bone area (Ct.Ar), eccentricity $(\mathrm{Ecc})$, maximum bending rigidity $\left(I_{\max }\right)$, and crosssectional thickness (Ct.Th). The threshold values for the micro$\mathrm{CT}$ analysis of trabecular bone were chosen to be between 60 and 255 and between 100 and 255 for cortical bone. All parameters were measured according to guidelines and nomenclature proposed by the American Society for Bone and Mineral Research (ASBMR) (28).

\section{Bone Histomorphometry}

Following micro-CT, tibiae of $\mathrm{db} / \mathrm{db}$ and lean mice were dehydrated in acetone for $24 \mathrm{~h}$ and embedded in methylmethacrylate (MMA, Sigma, UK) at low temperature. Unstained 8- $\mu$ m thick longitudinal sections were used for fluorescence microscopy to visualize mineralizing surfaces. The extent of the mineralizing surfaces was expressed as the alizarin red-labeled surfaces per unit bone surface (MS/BS). Mineral apposition rate (MAR) and bone formation rate (BFR) were calculated as previously described (14). Alternatively, sections were stained for tartrateresistant acid phosphatase (TRAP) (Leucognost ${ }^{\circledR}$ SP; Merck, Germany) and counterstained with Mayer's hematoxylin solution to visualize osteoclasts on trabecular bone, or subjected to Goldner's staining to quantify trabecular bone microarchitecture parameters. Parameters were measured in the trabecular bone of the metaphysis, using a $1 \mathrm{~mm}$ region of interest below the growth plate. Measurements were performed using image analysis software (Explora Nova, La Rochelle, France) and parameters were reported in accordance with the ASBMR nomenclature (29).

\section{Mechanical Testing}

Whole bone strength was assessed by three-point bending performed on the left femurs of $\mathrm{db} / \mathrm{db}$ and lean mice. Prior to mechanical testing, the femurs were hydrated in saline for $24 \mathrm{~h}$ at room temperature. Measurements were performed with a constant span length of $10 \mathrm{~mm}$ on an Instron 5942 (Instron, France). Femurs were positioned horizontally, with the anterior surface facing upward, centered on the support, and the pressing force was applied vertically to the bone midshaft. Each bone was tested with a loading speed of $2 \mathrm{~mm} / \mathrm{min}$ until failure with a $500 \mathrm{~N}$ load cell, as reported previously (13). The load-displacement curve was acquired using Bluehill 3 software (Instron) and ultimate load, ultimate displacement, stiffness, and work to fracture were quantified.

\section{Evaluation of Bone Mineral Density Distribution (BMDD)}

Quantitative backscattered electron imaging (qBEI) was employed to determine the BMDD in the MMA-embedded blocks above, as previously described (30). MMA blocks were carbon-coated and observed with a scanning electron microscope (EVO LS10, Carl Zeiss Ltd., Nanterre, France) equipped with a five-quadrant semi-conductor backscattered electron detector and operated at $20 \mathrm{keV}$, with a probe current of $250 \mathrm{pA}$ and a working distance of $15 \mathrm{~mm}$. The backscattered signal was calibrated as described (25). Four images per sample of cortical bone, centered $4 \mathrm{~mm}$ below the growth plate, were imaged at a $200 \times$ nominal magnification, corresponding to a pixel size of $0.5 \mu \mathrm{m}$. Analyses were performed to obtain variables from the BMDD: $\mathrm{Ca}_{\text {mean }}$, representing the average calcium concentration, $\mathrm{Ca}_{\text {peak }}$, the most frequently occurring calcium concentration, and $\mathrm{Ca}_{\text {width }}$, the width of the histogram at the half maximum level.

\section{Fourier-Transform Infrared Microscopy (FTIRM) at Sites of Bone Formation}

The same MMA-embedded blocks used for histomorphometry were utilized for FTIRM. Longitudinal tibia sections $(4-\mu \mathrm{m}$ thickness) were sandwiched between $\mathrm{BaF}_{2}$ optical windows. Spectral analysis was obtained on a Bruker Vertex 70 spectrometer (Bruker Optics, Germany) interfaced with a Bruker Hyperion 3000 infrared microscope. For FTIRM analysis at site of bone formation, 12 spectra on each bone were acquired between the alizarin red and calcein labeling and analyzed with Opus Software (release 6.5 , Bruker). The contribution of the embedding MMA and water vapor were corrected prior to baseline correction. Individual spectra were then subjected to curve fitting after obtaining a second derivative, using a commercially available software package (Grams/AI 8.0, Thermofisher Scientific, France). The parameters (25) were: (a) mineral-to-matrix ratio; (b) mineral maturity; (c) the carbonate-to-phosphate ratio; and (d) the collagen maturity index. All relevant calculations were described in Ref. (31).

\section{In Vitro Bone Formation by Primary Osteoblasts}

Primary mouse osteoblastic cells were obtained by sequential enzyme digestion of excised calvarial bones from 2-day-old C57BL/6 mice using a three-step process (32). Cells were cultured in minimum essential media (MEM) for 2-3 days at $37^{\circ} \mathrm{C}$ in $5 \% \mathrm{CO}_{2}$ until they reached confluence. They were then cultured in six-well trays in MEM supplemented with $2 \mathrm{mM}$ $\beta$-glycerophosphate and $50 \mu \mathrm{g} / \mathrm{mL}$ ascorbic acid, containing either normal $(5.5 \mathrm{mM})$ or high- $(22 \mathrm{mM})$ glucose concentrations, using mannitol (22 mM) as an osmotic control. Exenatide (0, 25, 
50 , and $100 \mathrm{nM}$ ) was added to the culture (one plate/treatment). Bone nodule formation by osteoblasts was measured after 28 days of culture. Experiments were terminated by fixing cell layers in $4 \%$ paraformaldehyde for $10 \mathrm{~min}$; mineralized bone nodules were visualized and quantified unstained. Bone nodules were scanned at 800 dpi using a high-resolution flat-bed scanner. Binary images of each individual well were then subjected to automated analysis (Image J), using constant "threshold" and "minimum particle" levels, to determine the number and surface area of mineralized bone nodules, as previously described (32).

\section{Statistics}

Data are presented as mean \pm SD except for acute blood flow where they are presented as mean \pm SEM to facilitate visibility. Multiple comparisons were performed using two-way analysis of variance and Tukey's multiple comparison post hoc test where appropriate. $P<0.05$ was considered to be statistically significant.

\section{RESULTS}

\section{Effect of Exenatide on Body Mass, Obesity Status, and Blood Glucose in $\mathrm{db} / \mathrm{db}$ Mice}

The development of diabetes in $\mathrm{db} / \mathrm{db}$ mice was identified by measuring body mass and blood glucose. The body mass of $\mathrm{db} / \mathrm{db}$ mice was significantly higher than that of lean mice at all time-points, consistent with severe obesity. Administration of Exenatide treatment for 4 weeks slightly reduced this in $\mathrm{db} / \mathrm{db}$ mice (by 6-7\%) compared with saline-treated $\mathrm{db} / \mathrm{db}$ mice $(P<0.01)$ despite the mice still being obese (Figure 1A). Exenatide had no effect in lean mice (Figure 1A).

Saline-treated $\mathrm{db} / \mathrm{db}$ mice exhibited dramatically higher blood glucose than saline-treated lean mice at 7-8 weeks [by 2.1 -fold $(P<0.001)$ ] and at $12-13$ weeks [by 3.5 -fold $(P<0.0001)$ ] (Figure 1B). The mice were all diabetic by 9 weeks of age. These data confirm significant impairment of glycemic control in these mice. Injection of Exenatide into $\mathrm{db} / \mathrm{db}$ mice decreased the blood glucose levels in the first week of treatment by $31 \%(P<0.0001)$ and in the last week by $42 \%(P<0.0001)$ compared with salinetreated $\mathrm{db} / \mathrm{db}$ mice. However, Exenatide had no effect on blood glucose in lean mice.

\section{Chronic and Acute Effects of Exenatide on Hindlimb Blood Flow in $\mathrm{db} / \mathrm{db}$ Mice}

Acute changes induced by Exenatide in hindlimb perfusion were measured by LDI in all mice. After 15 min injection, Exenatide significantly stimulated blood perfusion in tibiae of $\mathrm{db} / \mathrm{db}$ mice compared with the saline-treated ones. This vasodilatory effect of Exenatide increased over time for the $30 \mathrm{~min}$ following the injection, reaching a maximum $25 \%(P<0.0001)$ greater than that in saline-treated $\mathrm{db} / \mathrm{db}$ mice (Figures 2A,C). This increase in perfusion was also found in Exenatide-treated lean mice $(P<0.05)$ (Figure 2D).

Hindlimb perfusion was $44 \%$ lower in $\mathrm{db} / \mathrm{db}$ mice $(P<0.0001)$ than in lean mice (Figures 2B,E) confirming that diabetic mice have impaired blood flow. The chronic effect of Exenatide on hindlimb perfusion after 4 -week treatment was also assessed and our data show no differences in hindlimb perfusion between Exenatide-treated $\mathrm{db} / \mathrm{db}$ and Exenatide-treated lean mice (Figure 2E). These data indicate that acute but not chronic treatment with Exenatide increases hindlimb perfusion in $\mathrm{db} / \mathrm{db}$ and lean mice.

\section{Effect of Exenatide on Trabecular and Cortical Bone Microarchitecture in $\mathrm{db} / \mathrm{db}$ Mice}

We assessed the possible effects of Exenatide on trabecular and cortical bone microarchitecture. As expected, saline-treated $\mathrm{db} / \mathrm{db}$ mice exhibited lower trabecular bone mass and impaired micro-architectural parameters of connectivity and structure when compared with lean mice (Table 1). This low bone mass in $\mathrm{db} / \mathrm{db}$ mice was significantly improved by Exenatide treatment, as shown by an increase in BV/TV $(+49 \%, P<0.01)$ compared with saline-treated $\mathrm{db} / \mathrm{db}$ mice. This increase was associated with significant modifications of trabecular microarchitecture as
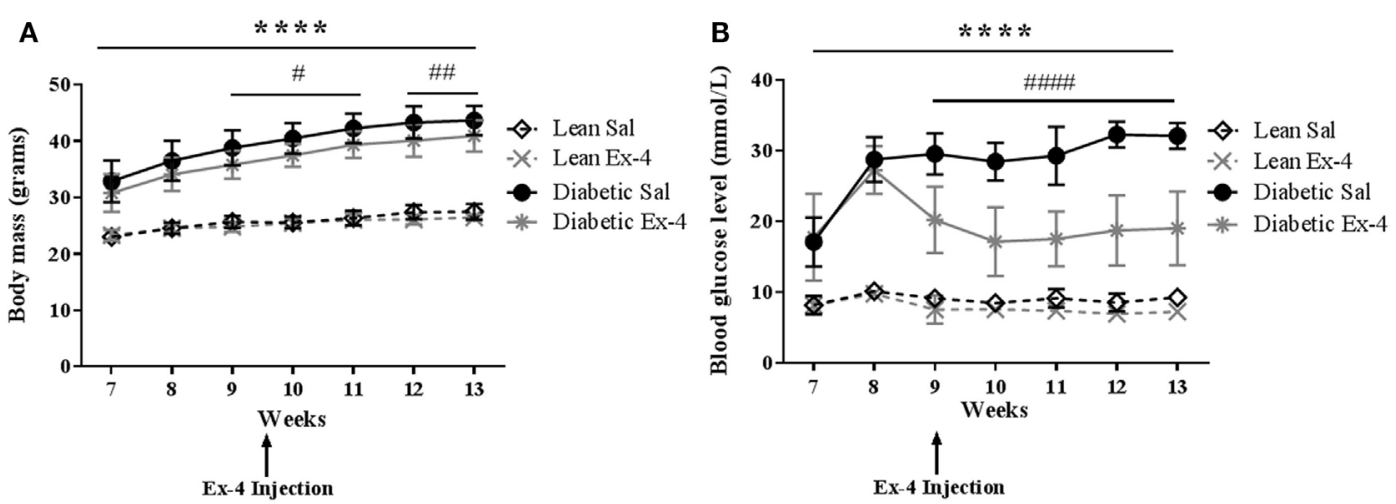

FIGURE 1 | Body mass and blood glucose in $\mathrm{db} / \mathrm{db}$ and control mice. Body mass and blood glucose levels were measured weekly in db/db and lean mice. Injections of Exenatide started at week 9 and continued daily for 4 weeks. (A) Body mass in relation to age in lean, diabetic, and Exenatide-treated mice from 7 to 13 weeks of age. (B) Blood glucose levels in lean, diabetic, and Exenatide-treated mice from 7 to 13 weeks of age. Bars represent mean \pm SD for $n=10$ mice/ group, ${ }^{\star \star \star \star} P<0.0001$ saline-treated diabetic versus saline-treated lean; ${ }^{\sharp} P<0.05$; ${ }^{\# \# \#} P<0.0001$ Exenatide-treated diabetic versus saline-treated diabetic mice. 
A

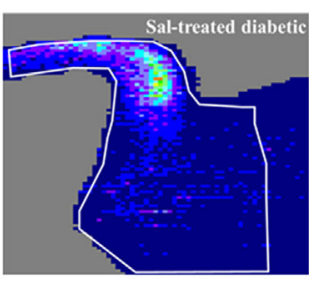

C

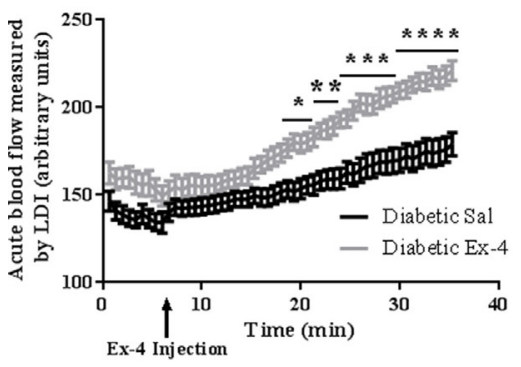

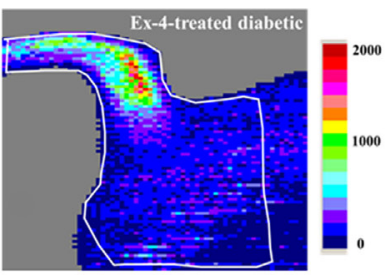

D

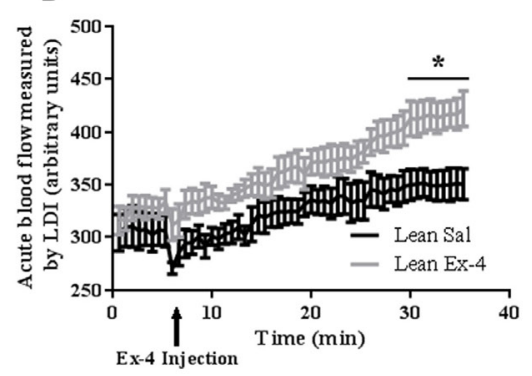

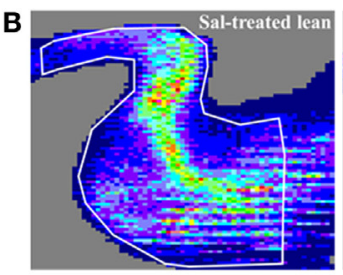
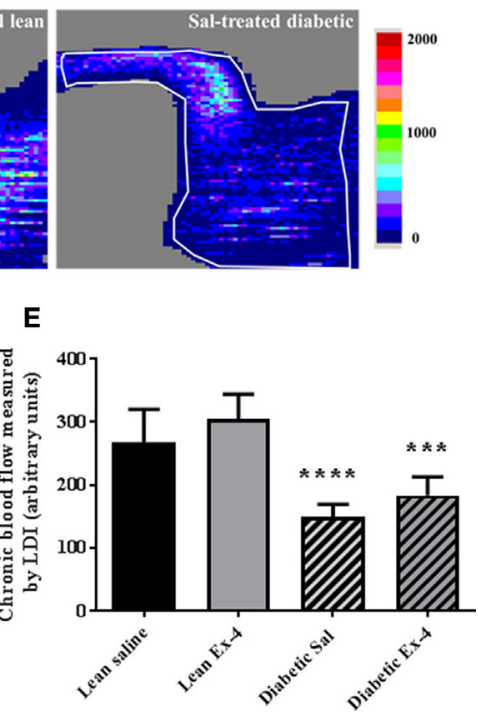

FIGURE 2 | Acute and chronic effects of Exenatide on hindlimb blood flow in db/db mice and control mice. (A,B) Representative images of mouse hindlimb perfusion, obtained by laser Doppler imaging (LDI). (A) Blood flow imaging of $\mathrm{db} / \mathrm{db}$ mice with saline injection versus Exenatide. Images were acquired after a 25 min infusion of saline or Exenatide (10 $\mu \mathrm{g} / \mathrm{kg} /$ day), (B) blood flow imaging of untreated lean mice versus $\mathrm{db} / \mathrm{db}$ mice. Images were acquired after the $4 \mathrm{weeks}$ of treatment. The colors in the heat maps indicate the maximum (red) and the minimum (blue) levels of perfusion, expressed in arbitrary units, representing the total blood flux (combination of velocity and concentration of red blood cells). (C,D) Time course graph of the average hindlimb perfusion monitored by LDI after Exenatide injection in $\mathrm{db} / \mathrm{db}$ (C) and lean (D) mice. Exenatide $(10 \mu \mathrm{g} / \mathrm{kg})$ and saline were injected to mice after 8 min of baseline recording. Values are presented as mean \pm SEM of $n=10$ mice/group, ${ }^{\star} P<0.05$; ${ }^{\star \star} P<0.01$; ${ }^{\star \star \star} P<0.001$; ${ }^{* \star \star \star} P<0.0001$ versus saline. (E) Differences in hindlimb blood flow measured by LDI between the groups after 4-week treatment with Exenatide. Bars represent mean $\pm \mathrm{SD}$ of $n=10$ mice/group, ${ }^{\star \star \star \star} P<0.0001$ versus lean mice.

evidenced by higher values for Tb.N $(+38 \%, P<0.01)$ and Tb.Th $(+8 \%, P<0.01)$ and lower values for microarchitecture, Tb.Pf $(-29 \% ; P<0.0001)$ and SMI $(-12 \% ; P<0.01)$ (Table 1). These beneficial effects of Exenatide in diabetic mice were confirmed by bone histomorphometry performed on 2D sections (Table 1). Tb.Sp was improved by Ex-4 with histomorphometry but not by micro-CT. One reason for this difference can be that measurements made by histomorphometry are performed in $2 \mathrm{D}$, in contrast to micro-CT where there are performed in $3 \mathrm{D}$, and are therefore less accurate. Indeed, in $3 \mathrm{D}, \mathrm{Tb} . \mathrm{Sp}$ is calculated independently of Tb.N and Tb.Th and it has been previously shown that derived Tb.Sp using 2D sections can be different from when measured directly in 3D and may yield in biased results (33).

Consistent with the trabecular bone changes, cortical bone geometry was also impaired in $\mathrm{db} / \mathrm{db}$ mice (Table 1 ). However, our results revealed no differences in any cortical parameter following Exenatide treatment of both lean and $\mathrm{db} / \mathrm{db}$ mice (Table 1).

\section{Effect of Exenatide on In Situ Bone Turnover in $\mathrm{db} / \mathrm{db}$ Mice}

We next examined whether amelioration of trabecular microarchitecture in Exenatide-treated $\mathrm{db} / \mathrm{db}$ mice was due to a change in osteoblast activity or osteoclast numbers. As expected, BFR/ $\mathrm{BS}$ was lower in $\mathrm{db} / \mathrm{db}$ mice than in lean mice. Exenatide treatment increased this parameter by $44.5 \%$ in $\mathrm{db} / \mathrm{db}$ mice $(P<0.01)$ compared with saline-treated ones. This augmentation in BFR/ BS was due to higher MAR (+28\%; $P<0.01$ ) (Figures 3A-C). On the other hand, Exenatide treatment had no effect in lean
TABLE 1 | Measurements of trabecular and cortical bone architecture in 13-week-old db/db and lean mice treated with either Ex-4 or saline.

\begin{tabular}{lcccc}
\hline Parameters & Lean saline & Lean Ex-4 & db/db saline & db/db Ex-4 \\
\hline \multicolumn{4}{l}{ Trabecular architecture using micro-CT } \\
BV/TV $(\%)$ & $7.21 \pm 1.37$ & $7.83 \pm 1.29$ & $3.35 \pm 0.51^{\star \star \star \star}$ & $5.00 \pm 0.78^{\# \#}$ \\
Tb.Th $(\mu \mathrm{m})$ & $57.4 \pm 2.9$ & $58.1 \pm 3.3$ & $45.3 \pm 2.2^{\star \star \star \star}$ & $49.1 \pm 1.8^{\# \#}$ \\
Tb.N $(/ \mathrm{mm})$ & $1.23 \pm 0.24$ & $1.36 \pm 0.21$ & $0.74 \pm 0.12^{\star \star \star \star}$ & $1.02 \pm 0.18^{\# \#}$ \\
Tb.Pf $(/ \mathrm{mm})$ & $17.00 \pm 4.78$ & $15.25 \pm 2.72$ & $28.89 \pm 2.10^{\star \star \star \star}$ & $20.62 \pm 2.94^{\# \# \# \#}$ \\
SMl & $1.9 \pm 0.21$ & $1.78 \pm 0.15$ & $2.18 \pm 0.09^{\star \star \star \star}$ & $1.93 \pm 0.13^{\# \#}$ \\
Tb.Sp $(\mathrm{mm})$ & $0.46 \pm 0.03$ & $0.45 \pm 0.04$ & $0.49 \pm 0.03$ & $0.46 \pm 0.04$
\end{tabular}

Trabecular architecture using histomorphometry

$\mathrm{BV} / \mathrm{TV}(\%) \quad 11.25 \pm 3.01 \quad 12.86 \pm 3.06 \quad 4.53 \pm 1.30^{\star \star \star \star} \quad 7.70 \pm 1.21^{\#}$

Tb.Th $(\mu \mathrm{m}) \quad 39.5 \pm 7.2 \quad 39.5 \pm 4.3 \quad 26.3 \pm 3.8^{\star \star \star \star} \quad 34.4 \pm 4.0^{\# \#}$

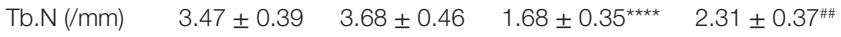

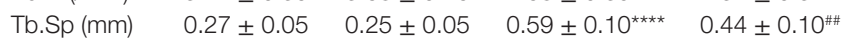

Cortical architecture using micro-CT

$\begin{array}{lllll}\text { Tt.Ar }\left(\mathrm{mm}^{2}\right) & 1.00 \pm 0.09 & 0.97 \pm 0.08 & 0.85 \pm 0.08^{\star \star} & 0.80 \pm 0.09\end{array}$

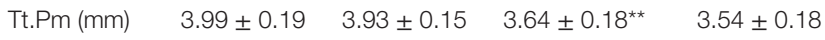

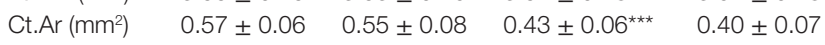

$\begin{array}{lllll}\text { Ecc } & 0.55 \pm 0.06 & 0.54 \pm 0.07 & 0.46 \pm 0.04^{*} & 0.45 \pm 0.09\end{array}$

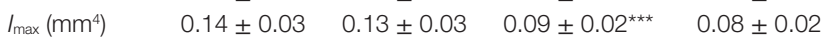

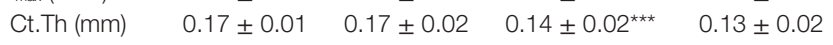

Measurements of trabecular architecture were performed in the proximal tibial metaphysis of $\mathrm{db} / \mathrm{db}$ and lean mice using micro-CT or histomorphometry. Measurements of cortical architecture were made using micro-CT in the tibial midshaft diaphysis of $d b / d b$ and lean mice.

BV/TV, bone volume percent; Tb.N, trabecular number; Tb.Pf, trabecular pattern factor; Tb.Th, trabecular thickness; Tb.Sp, trabecular separation; SMI, structure model index; Tt.Ar, tissue area; Tt.Pm, tissue perimeter; Ct.Ar, bone area; Ecc, eccentricity; Imax, maximal moment of inertia; Ct. Th, cross-sectional thickness.

Mean $\pm S D$ of $n=10$ mice/group. ${ }^{*} P<0.05$, ${ }^{* *} P<0.01,{ }^{* * *} P<0.001,{ }^{* * * *} P<0.0001$

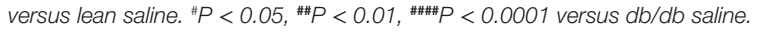



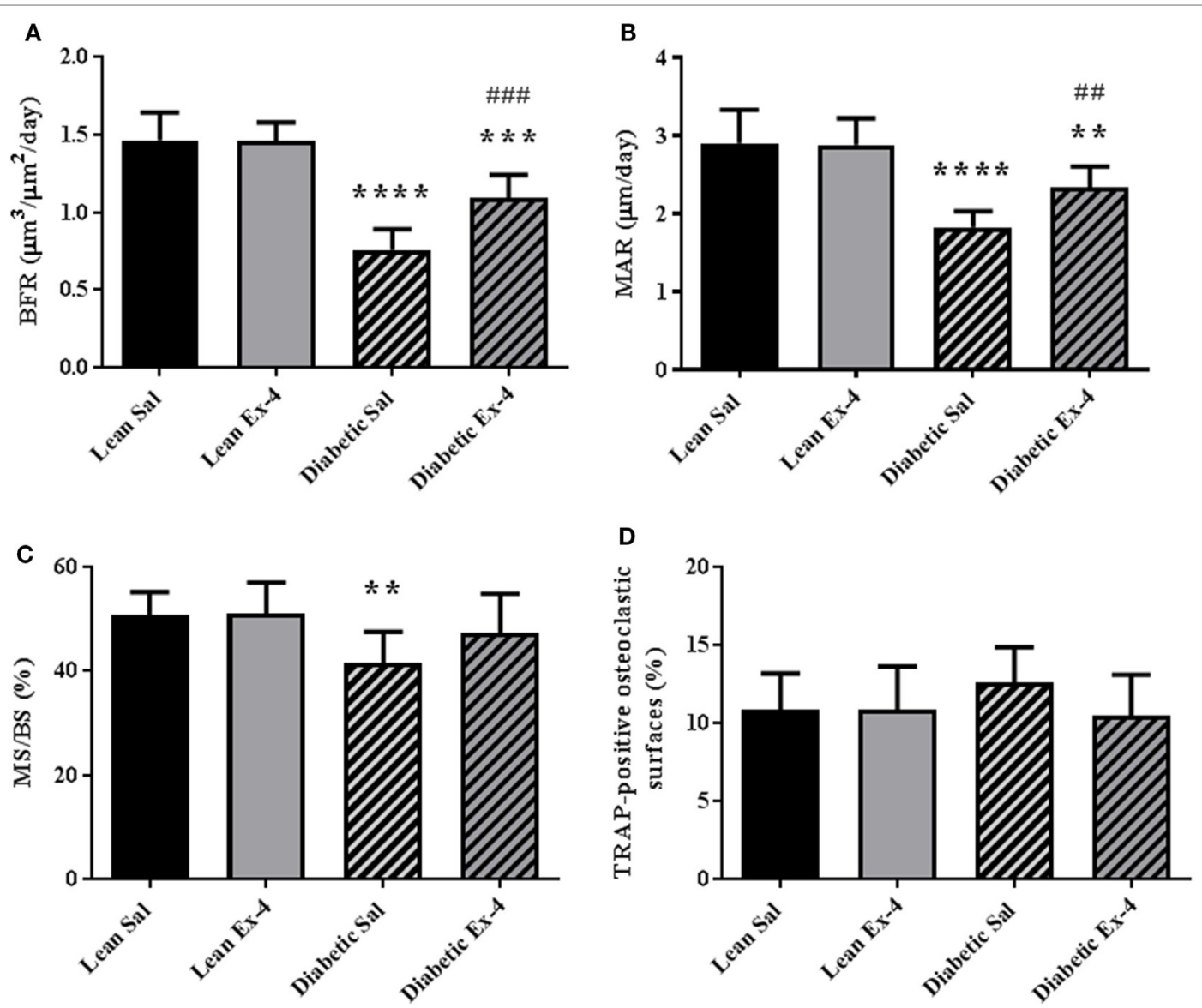

FIGURE 3 | Effect of Exenatide on bone turnover parameters in $\mathrm{db} / \mathrm{db}$ and control mice. Measurements were performed by bone histomorphometry on the trabecular region of tibial sections from 13-week-old db/db and lean mice treated with either Exenatide (10 $\mu \mathrm{g} / \mathrm{kg} / \mathrm{day})$ or saline. (A) Bone formation rate (BFR). (B) Mineral apposition rate (MAR). (C) Mineralizing surfaces MS/BS. (D) Tartrate-resistant acid phosphatase (TRAP)-positive osteoclastic surfaces per millimeter of trabecular bone surface. Bars represent mean \pm SD of $n=10$ mice/group, ${ }^{\star \star} P<0.01,{ }^{\star \star \star} P<0.001$, ${ }^{\star \star \star \star} P<0.0001$ versus lean Sal; ${ }^{\# \#} P<0.01$, \#\#\# $P<0.001$ versus diabetic Sal.

mice. We did not observe any significant differences in the number of TRAP-positive osteoclastic surfaces among the groups (Figure 3D), suggesting that bone resorption was not affected by diabetes or Exenatide treatment in lean and diabetic animals.

\section{Effect of Exenatide on In Vitro Bone Formation in High-Glucose Conditions}

In order to assess whether the above effects were due to direct action of exenatide on bone cells, we investigated the effect of Exenatide on bone formation by primary osteoblasts under high-glucose conditions. Similar to our previous findings (14), we found no effect of Exenatide on bone formation in vitro when osteoblasts were cultured in normal glucose concentrations. In contrast, a sevenfold reduction $(P<0.0001)$ in bone nodule formation was observed under high-glucose conditions (Figure 4A). The area of bone nodule formation in the presence of mannitol was similar to that generated in normal glucose conditions, suggesting that the inhibition of bone formation observed in high-glucose medium was not induced by extracellular hyperosmolarity. Exenatide treatment increased the area of bone nodule formation by osteoblasts cultured in high-glucose medium by twofold $(P<0.001)$ and threefold $(P<0.0001)$ with concentrations of 50 and $100 \mathrm{nM}$, respectively, while it had no effect when osteoblasts were cultured in low-glucose concentrations (Figure 4B).

\section{Effect of Exenatide on Bone Mechanical Strength in $\mathrm{db} / \mathrm{db}$ Mice}

Figure 5A represents an example of load/deformation curves that were recorded in the four groups. As expected, $\mathrm{db} / \mathrm{db}$ mice had compromised bone strength evidenced by reductions in ultimate load, stiffness, and work-to-failure. Treatment of $\mathrm{db} / \mathrm{db}$ mice with Exenatide led to a slight but not significant increase in ultimate load, stiffness, and work-to-failure (Figure 5).

\section{Effect of Exenatide on BMDD in $\mathrm{db} / \mathrm{db}$ Mice}

We aimed to look at modifications of the BMDD to see any possible alteration in the calcium content of cortical bone (Figure 6A). 

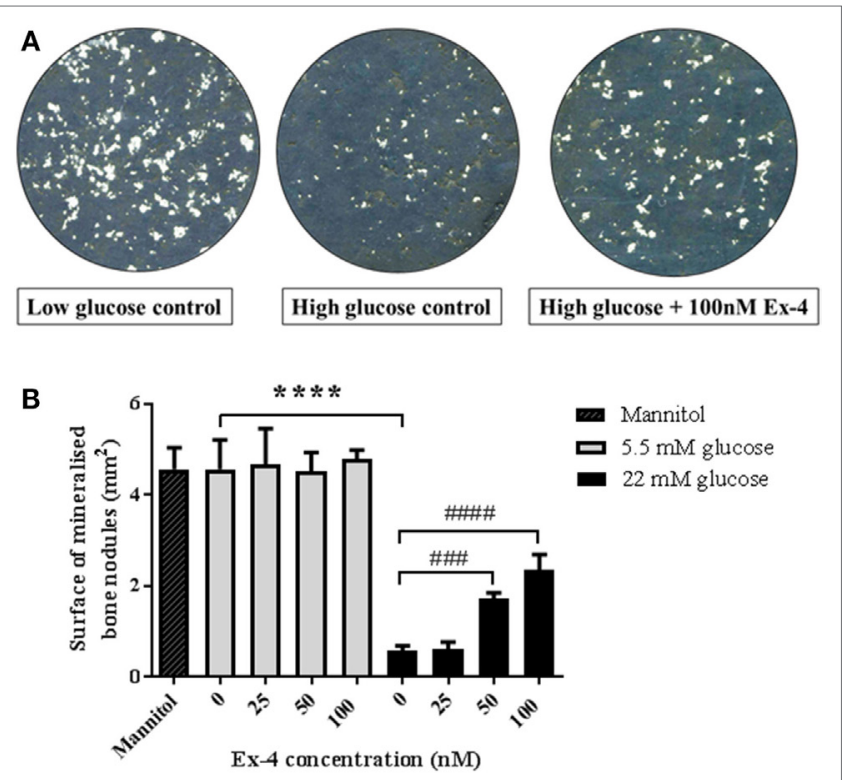

FIGURE 4 | Effects of Exenatide on bone nodule formation in vitro under normal and high-glucose conditions. Mouse primary osteoblasts were isolated from calvaria of 2-3 days old pups and cultured for 28 days in six-well plates in osteogenic medium (with addition of ascorbate and $\beta$-glycerophosphate) in either normal $(5.5 \mathrm{mM})$ or high- $(22 \mathrm{mM})$ glucose concentration. Exenatide was added to the cells in normal and high-glucose conditions at various concentrations $(0,25,50$, and $100 \mathrm{nM})$. A control with $22 \mathrm{mM}$ of mannitol was used as an osmotic control to ensure that changes in bone formation is due to glucotoxicity rather than hyperosmolarity. Mineralized nodules representing bone formation were scanned and observed unstained. Quantification of mineralization was performed using Image J. (A) Imaging of bone nodules using contrasting color on photoshop to visualize the bone nodules that appear in white. (B) Quantification of the area of bone formation by osteoblasts cultured with glucose and Exenatide. Mean \pm SD of six wells/group. ${ }^{\star \star \star \star} P<0.0001$ versus low glucose condition;

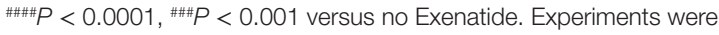
performed three times in triplicates and graphs are representative of one experiment

$\mathrm{Ca}_{\text {width }}$, that represents heterogeneity in mineral content, was 9.5\% $(P<0.05)$ lower in $\mathrm{db} / \mathrm{db}$ mice compared with lean mice (Figure 6B). Four weeks' treatment with Exenatide increased the $\mathrm{Ca}_{\text {width }}$ by $17 \%(P<0.001)$ in $\mathrm{db} / \mathrm{db}$ mice compared with salinetreated ones (Figure 6B), but had no effect on lean mice. $\mathrm{Ca}_{\text {mean }}$ and $\mathrm{Ca}_{\text {peak }}$ were not modified by diabetes or Exenatide treatment (Figures 6C,D), indicating that the average calcium concentration was not affected by either.

\section{Effect of Exenatide on Tissue Material Properties at Bone Formation Sites in $\mathrm{db} / \mathrm{db}$ Mice}

Because there was no alteration in the calcium content of cortical bone in $\mathrm{db} / \mathrm{db}$ mice, tissue material properties were investigated at bone formation sites using FTIRM. Mineral/matrix ratio, mineral maturity, and carbonate/phosphate ratio were similar in the four groups of animals (Figures 7A-C). However, $\mathrm{db} / \mathrm{db}$ mice showed lower collagen maturity $(-25 \%, P<0.01)$ than lean mice (Figure 7D). Treatment with Exenatide significantly increased collagen maturity $(+47 \%, P<0.001)$ in $\mathrm{db} / \mathrm{db}$ mice but had no effect on lean mice (Figure 7D).

\section{DISCUSSION}

Among all complications of diabetes mellitus, bone frailty is often disregarded by diabetologists despite its high impact on life quality. Bone fragility is certainly a consequence of chronic hyperglycemia but can also result of direct or indirect effects of anti-diabetic drugs. With respect to the conflicting results on BMD in T2DM, the underlying mechanisms of bone fragility in T2DM seems to be related to the quality rather than the quantity of bone tissue, and as such, it is absolutely crucial to ascertain how marketed anti-diabetic drugs influence bone quality. In the present study, we thought to investigate how Exenatide, a GLP-1 receptor agonist, marketed for the treatment of type 2 diabetes, influences bone quality, remodeling, and strength in a murine model of genetically inherited T2DM that reproduces several features of human diabetes. Four weeks' treatment with Exenatide was sufficient to improve trabecular bone in T2DM mice by increasing bone formation, which could possibly due to the observed acute increase in skeletal perfusion. While Exenatide did not show significant effect on bone strength and mineral, it improved the properties of the matrix by increasing the collagen maturity in site of new bone formation. In vitro data suggest that Exenatide can promote bone formation by osteoblasts when cultured only in high-glucose concentrations.

Leptin has been shown to induce a negative energy balance by reducing appetite and increasing energy expenditure (34). Although not all obese patients would develop diabetes, most patients with T2DM are obese (35). Leptin circulates in serum at levels that mirrors body fat. However, obese individuals have been found to be resistant to leptin action (36). The long form of the leptin receptor is encoded by the $d b$ gene and a recessive mutation in this gene has been shown to affect the intracellular domain of the single membrane-spanning receptor (37). Although leptin appears to bind to its receptor in mutant homozygous $d b / d b$ mice (38), defective intracellular signal transduction attenuates leptin function, leading to a characteristic phenotype of severe obesity and diabetes, similar to what is observed in most human T2DM patients $(39,40)$, and replicated in the present study as demonstrated by low-bone mass and severe diabetes. As such, although leptin can also have effects on bone independently of diabetes $(41,42)$, the $\mathrm{db} /$ $\mathrm{db}$ mouse represents a good model of T2DM, and reproduces the bone phenotype observed in most T2DM. In accordance with the literature, chronic administration of Exenatide reduced non-fasting plasma glucose in $\mathrm{db} / \mathrm{db}$ mice (43). It also caused a slight reduction in the body mass of these mice, likely due to the effect of Exenatide on the central nervous system, where it enhances satiety and diminishes food consumption (44).

Previously, improvement in trabecular bone mass have been reported in diabetic rodents (cholecystokinin receptor A-deficient OLETF rats and Goto-Kakizaki rats) or rodent models of ovariectomy-induced osteoporosis in response to GLP-1RAs $(7,9,11,14)$. However, although our study confirms this finding in the leptin receptor-deficient mice, it also further 

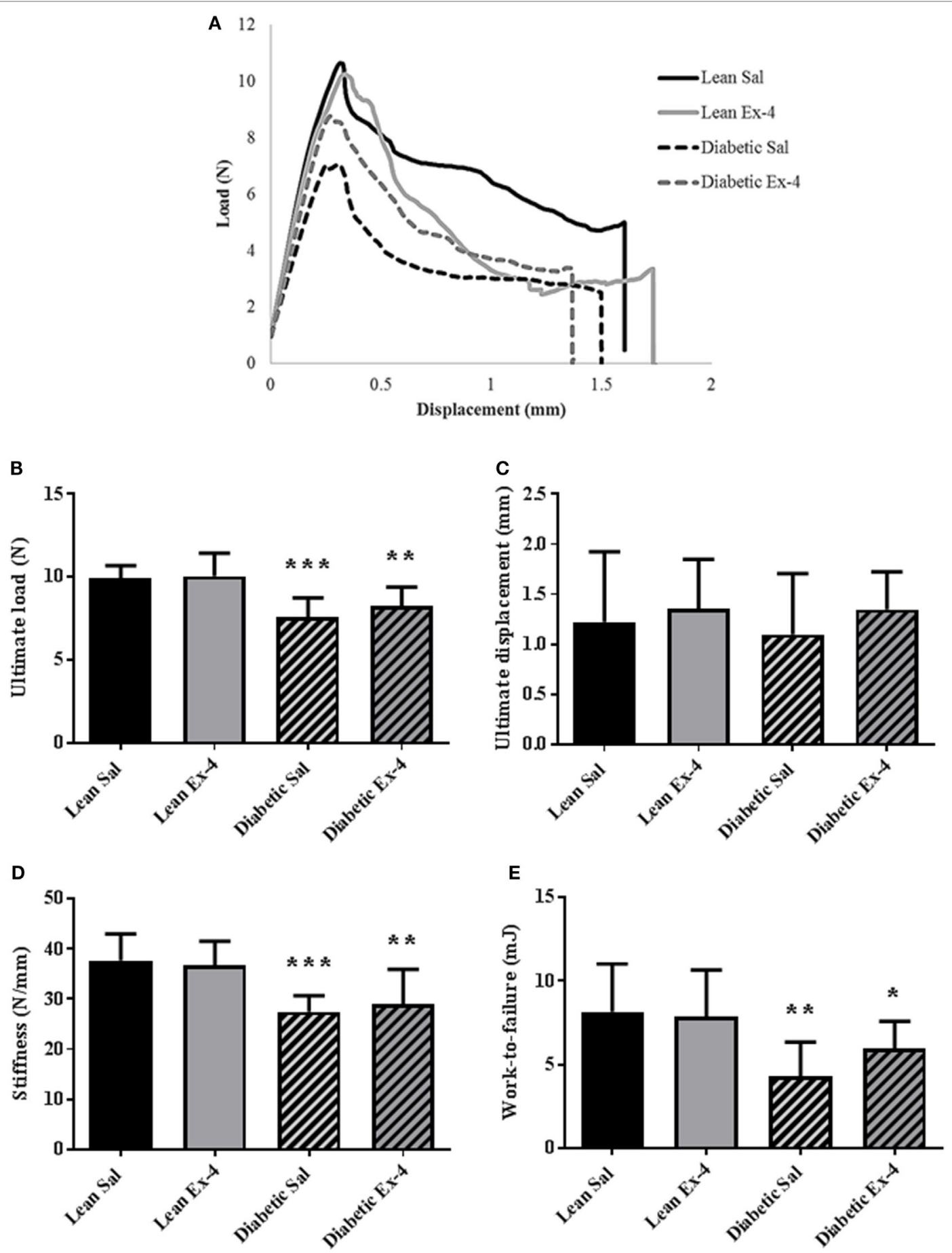

FIGURE 5 | Effect of Exenatide on trabecular bone strength in $\mathrm{db} / \mathrm{db}$ and control mice. Mechanical parameters were recorded in whole left femur using three-point bending in 13-week-old db/db and lean mice treated with either Exenatide (10 $\mu \mathrm{g} / \mathrm{kg} /$ day) or saline. (A) Examples of load-displacement curves. (B) Ultimate load. (C) Ultimate displacement. (D) Stiffness. (E) Work-to-failure. Bars represent mean \pm SD of $n=10$ mice/group, ${ }^{\star} P<0.05$, ${ }^{* \star} P<0.01$, ${ }^{\star \star \star} P<0.001$ versus lean Sal.

augments our knowledge about the effects of such therapy on bone quality that is compromised in animal models of T2DM but also in human diabetic individuals. While Exenatide showed an anabolic effect in diabetic mice, it did not affect bone mass and quality in lean mice, similarly to a previous study (8). Exenatide reversed the low-osteoblast activity observed in saline-treated mice (augmentations of BFR/BS and MAR, no decrease in MS/BS) suggesting that this molecule acts on diabetic bone as an anabolic agent. Our results suggest also an uncoupling effect, in diabetes, as observed by the lack of effect on osteoclast 


\section{A}

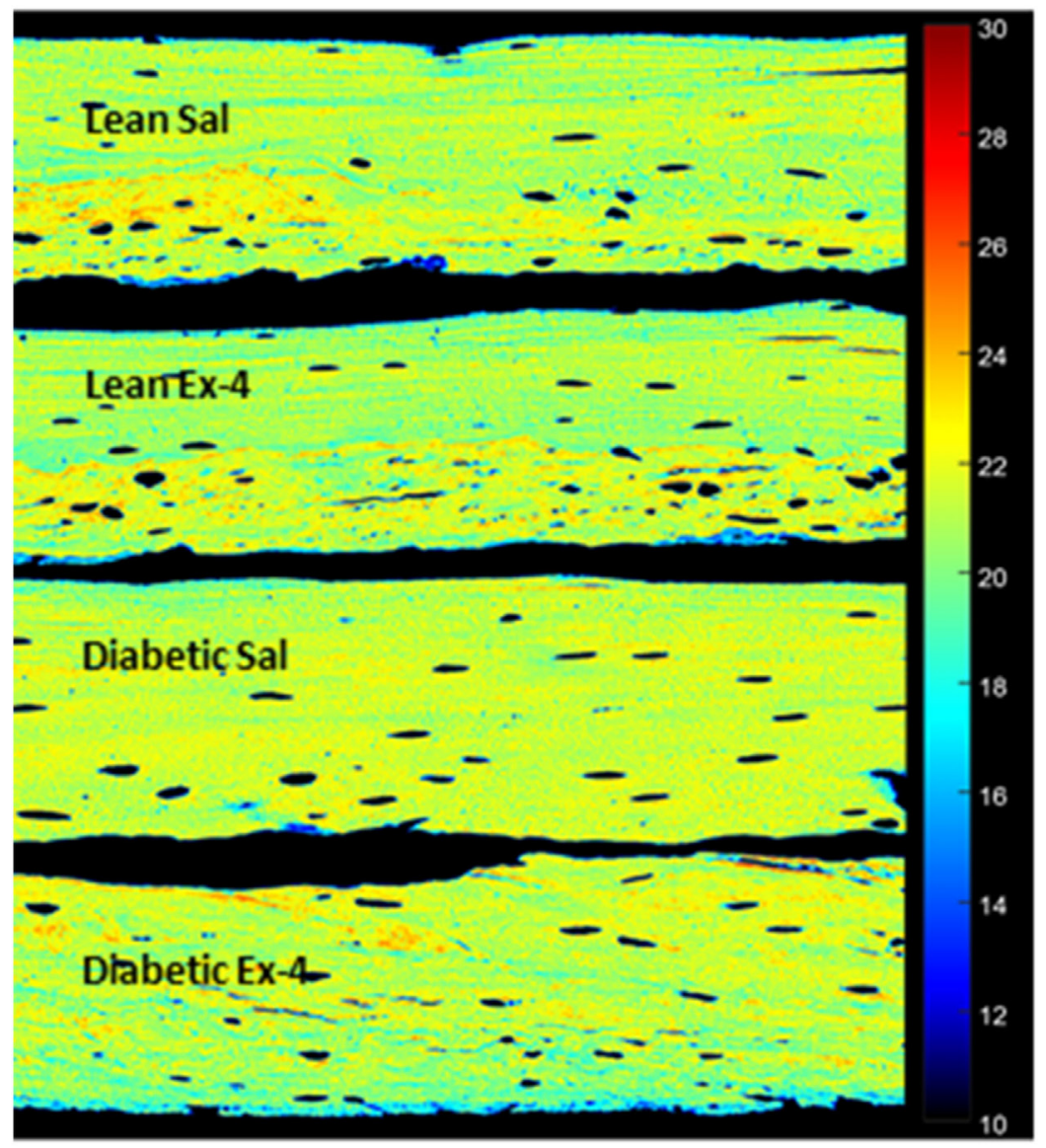

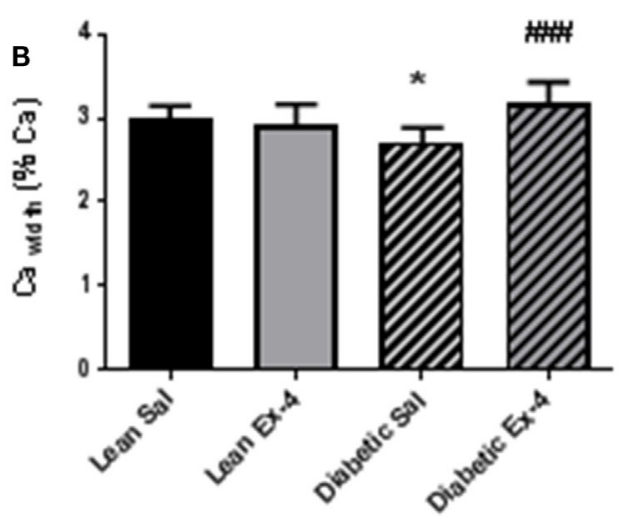
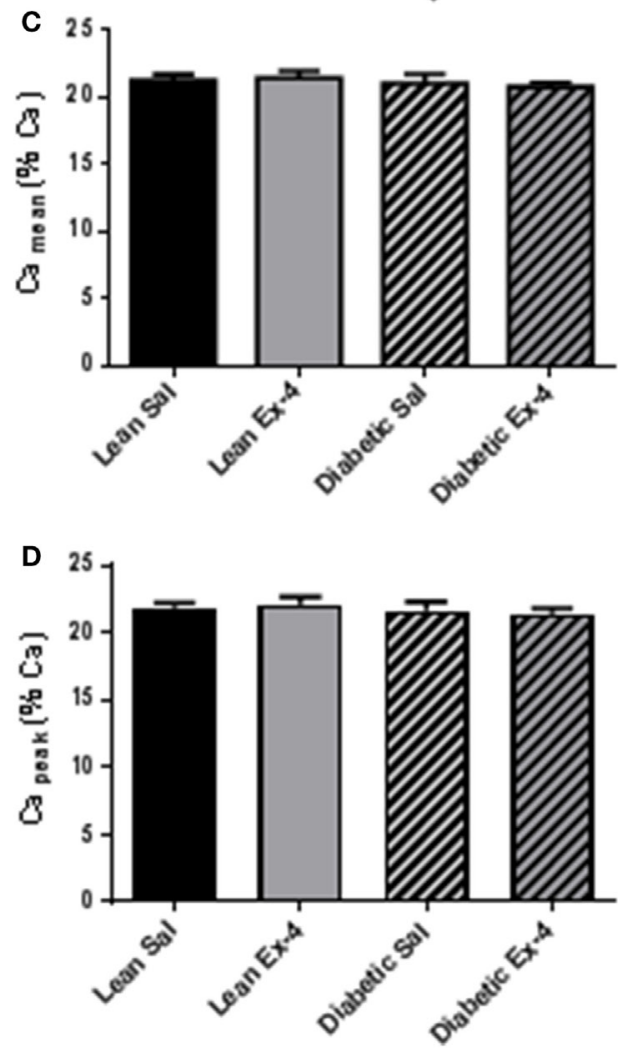

FIGURE 6 | Effect of Exenatide on bone mineral density distribution (BMDD) in $\mathrm{db} / \mathrm{db}$ and control mice. Quantitative backscattered electron imaging was employed to determine the BMDD in tibial methylmethacrylate-embedded blocks from 13-week-old db/db and lean mice treated with either Exenatide (10 $\mu \mathrm{g} / \mathrm{kg} / \mathrm{day}$ ) or saline. (A) Representative calcium (Ca) map. (B) Characterization of BMDD by Ca width. (C) Characterization of BMDD by Ca mean. (D) Characterization of BMDD by Ca peak. Bars represent mean $\pm \mathrm{SD}$ of $n=10$ mice/group, ${ }^{*} P<0.05$ versus lean Sal; \#\# $P<0.001$ versus diabetic Sal.

surface, although it is not a measure of osteoclast activity. This finding seems in opposition to our previous published data that showed increased osteoclast surfaces and numbers with Exenatide in a mouse model of ovariectomy-induced osteoporosis (14). This could be attributed to the animal models used. The $\mathrm{db} / \mathrm{db}$ mouse model is not solely an obese-diabetic model and alterations in bone turnover could be attributed to changes in leptin signaling and other hormonal levels. Furthermore, region-specific differences in bone turnover in $\mathrm{db} / \mathrm{db}$ mice have been shown, with both bone formation and bone resorption being either decreased or increased (45). Unfortunately, we were not able to analyze osteoclastogenesis and in vitro bone resorption by osteoclasts isolated from $\mathrm{db} / \mathrm{db}$ mice to clarify this inconsistency.

Furthermore, at site of bone formation, Exenatide was capable of augmenting collagen maturity that is compromised in salinetreated diabetic mice. The anabolic action of Exenatide can also be observed in the higher mineralization heterogeneity observed by qBEI that first restore levels similar to non-diabetic animals and second reflect the new bone formation that is not yet fully mineralized. The latter can also be evaluated from the lower, but not significant, $\mathrm{Ca}_{\text {mean }}$ values. 

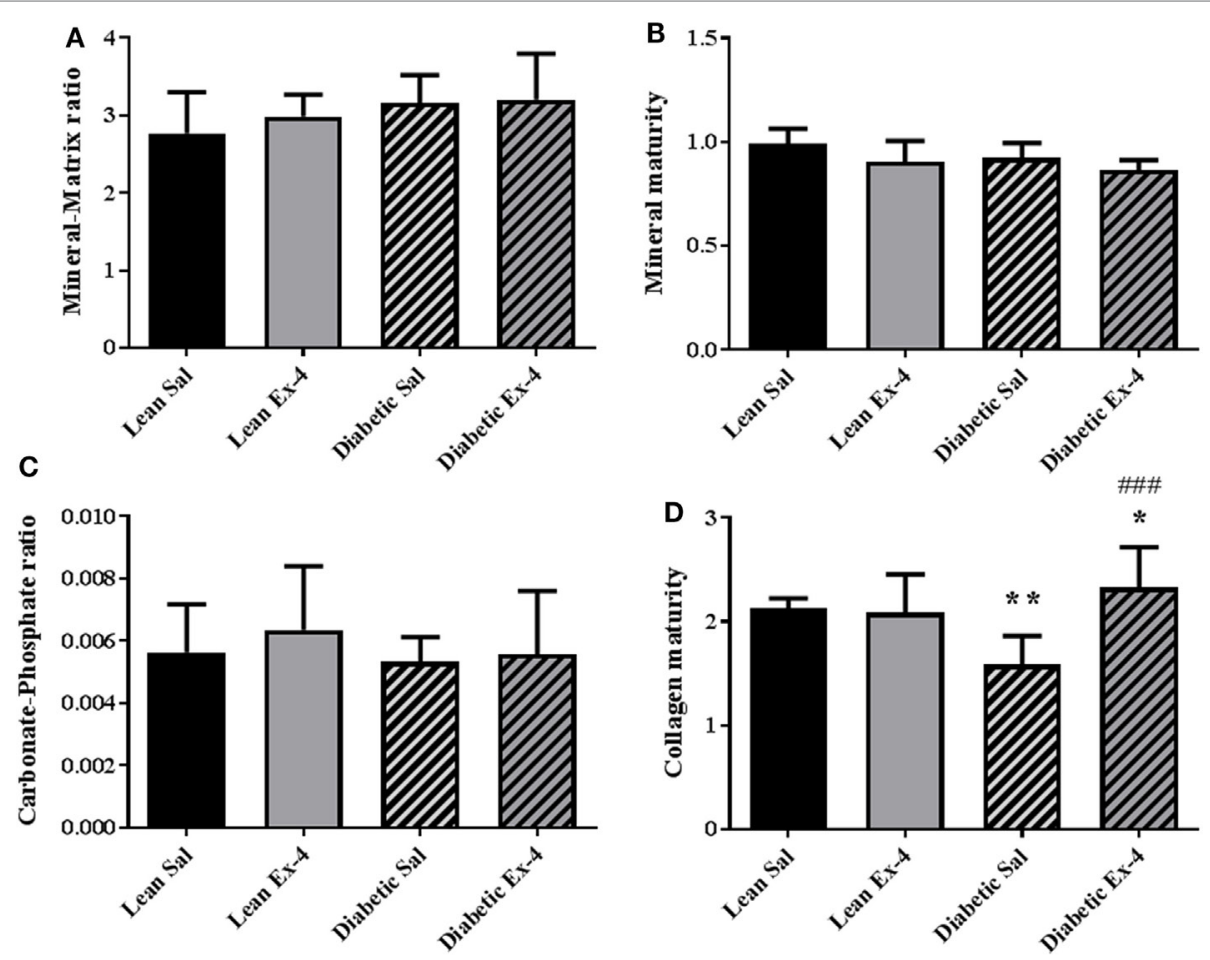

FIGURE 7 | Effect of Exenatide on tissue material properties assessed at bone formation sites in db/db and control mice. Measurements were performed by Fourier-transform infrared microscopy between the fluorescent labels of the trabecular region of tibial sections in 13-week-old db/db and lean mice treated with either Exenatide or saline. (A) Mineral-to-matrix ratio. (B) Mineral maturity. (C) Carbonate-to-phosphate ratio. (D) Collagen maturity index. Bars represent mean \pm SD of $n=10$ mice/group, ${ }^{\star} P<0.05,{ }^{\star \star} P<0.01$ versus lean Sal; ${ }^{\# \#} P<0.001$ versus diabetic Sal.

Taken all together, our results support the idea that Exenatide ameliorates the bone phenotype, in diabetic mice, through an increase in bone formation and that the drug has no effect in non-diabetic conditions. It is, however, still not very clear whether the increase in bone formation is due to direct effects of Exenatide on osteoblasts or to systemic effects. It has been shown that the GLP-1R is expressed in marrow mesenchymal cells including adipocytes and osteoblasts $(14,46)$, suggesting that the effects of Exenatide on bone formation could be direct by binding to the GLP-1R expressed on osteoblasts. Therefore, we tested the direct effects of Exenatide on osteoblasts in vitro in low- and high-glucose concentrations. Exposure of primary osteoblasts to high-glucose concentrations inhibited in vitro bone nodule formation, consistent with previous in vitro studies $(47,48)$. Addition of Exenatide in confluent primary osteoblasts cultured in normal glucose conditions did not affect bone nodule formation, in accordance with our previous findings showing that Exenatide has no effect on bone formation in non-hyperglycemic conditions (14). Studies conducted to examine the direct effects of GLP-1 agonists on in vitro bone formation have led to inconsistent results. Exenatide and Liraglutide were shown to promote proliferation and differentiation of a pre-osteoblastic cell line (MC3T3-E1) by direct binding to the GLP-1R, suggesting that GLP-1RAs could promote osteoblast-mediated bone formation (49-51). However, another study has yielded opposite results using the same cell line (52). However, the MC3T3-E1 cell line does not form trabecular bone nodules, contrary to primary osteoblasts used in our study. We cannot exclude, however, that Exenatide may exert a direct anabolic effect on bone by increasing proliferation and differentiation of osteoblasts rather than affecting their bone forming activity. Interestingly, Exenatide directly reduced the deleterious effect of glucose on bone formation in a dose-dependent manner, while it had no effect under normal glucose conditions. This is in agreement with our in vivo observation showing that Exenatide exerts no effect in lean mice. The mechanisms for the possible protective effects of GLP-1RAs against the adverse action of glucose on osteoblasts are still unclear. Previous data indicate that culture of osteoblasts in highglucose concentrations increases the expression levels of GLP-1R mRNA (53), suggesting that GLP-1R may directly link bone and glucose metabolism in osteoblasts. Therefore, the observed increase in bone formation caused by Exenatide in the presence of high-glucose concentrations might be due to upregulated GLP-1R expression, which could in turn magnify the effect direct effect of GLP-1RAs on osteoblasts. A recent study shows that GLP-1RAs facilitate glucose uptake in skeletal muscle cells by activating the AMP-activated protein kinase (54). Consequently, GLP-1RAs could improve glucose uptake by osteoblasts therefore reducing glucotoxicity. This hypothesis needs, however, to be confirmed by future overexpression or knockout of GLP-1R studies and by testing of insulin signaling and glucose metabolism in osteoblasts in response to Exenatide. 
Alternatively, GLP-1RAs may increase bone mass by a systemic effect such as an increase in bone blood flow. Patients with T2DM demonstrate cardiovascular complications, including endothelial dysfunction and impaired vasodilatation (55). Therefore, it would be expected that the blood flow to bone is reduced with diabetes. The reference method to measure bone blood flow is the intravascular injection of labeled microspheres (56). However, a strong correlation was found between the standardized measure of bone blood flow and hindlimb perfusion measured using LDI (57), indicating that measuring whole hindlimb blood flow is a good surrogate method. Similar to what has been observed in humans (55), our diabetic mice demonstrated impaired blood flow, indicated by a decrease in hindlimb perfusion. This is in accordance with a previous study that showed lower bone and bone marrow perfusion in Zucker diabetic rats and suggested that impairment of the bone circulation may contribute to the osteopenia observed in these rats (58). Furthermore, we have shown that Exenatide acutely increased hindlimb perfusion. Similar vasodilator effects of Exenatide have been demonstrated in ex vivo studies with dilation of the rat femoral artery (59) and thoracic aorta (60). However, only one clinical study performed in overweight men has shown a beneficial effect of Exenatide on capillary perfusion using the laser Doppler technique (61). Consistent with our data, the effects of Exenatide were observed rapidly, suggesting direct actions of Exenatide on vascular perfusion.

The increased bone formation observed in $\mathrm{db} / \mathrm{db}$ mice treated with Exenatide could be attributed in part to the increased skeletal perfusion. Blood supply plays a key role in bone formation by transporting oxygen, osteoprogenitor cells, and growth factors released from endothelial cells, which control the recruitment, proliferation, differentiation, and function of osteoblasts and osteoclasts (62). Because vasodilation and angiogenesis both contribute to bone blood supply, changes in blood flow could indirectly affect bone formation. Since decreased bone formation occurs concurrent with reduced hindlimb perfusion in $\mathrm{db} / \mathrm{db}$ mice, this suggests that insufficient perfusion could restrain bone formation. This contention is supported by the fact that elderly

\section{REFERENCES}

1. Yamamoto M, Yamaguchi T, Yamauchi M, Kaji H, Sugimoto T. Diabetic patients have an increased risk of vertebral fractures independent of BMD or diabetic complications. J Bone Miner Res (2009) 24(4):702-9. doi:10.1359/ jbmr.081207

2. Yamamoto M. Insights into bone fragility in diabetes: the crucial role of bone quality on skeletal strength. Endocr J (2015) 62(4):299-308. doi:10.1507/ endocrj.EJ15-0129

3. Yamamoto M, Sugimoto T. Advanced glycation end products, diabetes, and bone strength. Curr Osteoporos Rep (2016) 14(6):320-6. doi:10.1007/ s11914-016-0332-1

4. Karim L, Bouxsein ML. Effect of type 2 diabetes-related non-enzymatic glycation on bone biomechanical properties. Bone (2016) 82:21-7. doi:10.1016/j. bone.2015.07.028

5. Napoli N, Chandran M, Pierroz DD, Abrahamsen B, Schwartz AV, Ferrari SL, et al. Mechanisms of diabetes mellitus-induced bone fragility. Nat Rev Endocrinol (2017) 13(4):208-19. doi:10.1038/nrendo.2016.153

6. Baggio LL, Drucker DJ. Glucagon-like peptide-1 receptors in the brain: controlling food intake and body weight. J Clin Invest (2014) 124(10):4223-6. doi:10.1172/JCI78371 women with osteoporosis have reduced femoral blood flow (63). Increased perfusion resulting from Exenatide treatment could ameliorate this defect.

Our experiments were performed in male $\mathrm{db} / \mathrm{db}$ mice that exhibit more severe clinical symptoms and we cannot exclude potential gender differences regarding the skeletal effects of Exenatide in $\mathrm{db} / \mathrm{db}$ mice. T2DM women treated with Exenatide presented more benefit in terms of cardiovascular risk factor and body weight (64) that can be attributed to interaction of Exenatide with estrogen signaling (65). As there is increased fracture risk among T2DM women compared with men, it would be of interest to verify our findings in female T2DM models in order to have sex-specific treatment guidelines.

In conclusion, administration of Exenatide to leptin receptordeficient $\mathrm{db} / \mathrm{db}$ mice improves bone mass, microarchitecture, and quality possibly by (1) reversing the impaired bone formation induced by glucose, (2) stimulating bone formation systemically via increased hindlimb perfusion, and (3) improving collagen content. This study provides additional evidence for the inclusion of GLP-1RAs in therapeutic strategies for diabetic patients with concurrent bone disease.

\section{AUTHOR CONTRIBUTIONS}

Study design: MP, CC, and MC. Study conduct: MP, SG, and GM. Data collection: MP, SG, and GM. Data analysis: MP, SG, and GM. Data interpretation: MP, GM, JR, and CC. Drafting manuscript: MP and CC. Revising manuscript content: SG, GM, JR, AF, and MC. Approving final version of manuscript: MP, CC, SG, GM, $\mathrm{JR}, \mathrm{AF}$, and $\mathrm{MC}$ take responsibility for the integrity of the data analysis.

\section{FUNDING}

This research was financially supported by Orthopedic Research UK (grant 516, 2014) and the Society for Endocrinology (an early career grant, 2015).
7. Nuche-Berenguer B, Lozano D, Gutierrez-Rojas I, Moreno P, Marinoso ML, Esbrit P, et al. GLP-1 and exendin-4 can reverse hyperlipidic-related osteopenia. J Endocrinol (2011) 209(2):203-10. doi:10.1530/JOE-11-0015

8. Nuche-Berenguer B, Moreno P, Portal-Nunez S, Dapia S, Esbrit P, VillanuevaPenacarrillo ML. Exendin-4 exerts osteogenic actions in insulin-resistant and type 2 diabetic states. Regul Pept (2010) 159(1-3):61-6. doi:10.1016/j. regpep.2009.06.010

9. Kim JY, Lee SK, Jo KJ, Song DY, Lim DM, Park KY, et al. Exendin-4 increases bone mineral density in type 2 diabetic OLETF rats potentially through the down-regulation of SOST/sclerostin in osteocytes. Life Sci (2013) 92(10):53340. doi:10.1016/j.lfs.2013.01.001

10. Sun HX, Lu N, Luo X, Zhao L, Liu JM. Liraglutide, the glucagon-like peptide-1 receptor agonist, has anabolic bone effects in diabetic Goto-Kakizaki rats. J Diabetes (2015) 7(4):584-8. doi:10.1111/1753-0407.12282

11. Ma X, Meng J, Jia M, Bi L, Zhou Y, Wang Y, et al. Exendin-4, a glucagon-like peptide-1 receptor agonist, prevents osteopenia by promoting bone formation and suppressing bone resorption in aged ovariectomized rats. J Bone Miner Res (2013) 28(7):1641-52. doi:10.1002/jbmr.1898

12. Mabilleau G, Mieczkowska A, Irwin N, Flatt PR, Chappard D. Optimal bone mechanical and material properties require a functional glucagon-like peptide-1 receptor. J Endocrinol (2013) 219(1):59-68. doi:10.1530/JOE-13-0146 
13. Mieczkowska A, Mansur S, Bouvard B, Flatt PR, Thorens B, Irwin N, et al. Double incretin receptor knock-out (DIRKO) mice present with alterations of trabecular and cortical micromorphology and bone strength. Osteoporos Int (2015) 26(1):209-18. doi:10.1007/s00198-014-2845-8

14. Pereira M, Jeyabalan J, Jorgensen CS, Hopkinson M, Al-Jazzar A, Roux JP, et al. Chronic administration of glucagon-like peptide-1 receptor agonists improves trabecular bone mass and architecture in ovariectomised mice. Bone (2015) 81:459-67. doi:10.1016/j.bone.2015.08.006

15. Marenzana M, Arnett TR. The key role of the blood supply to bone. Bone Res (2013) 1(3):203-15. doi:10.4248/BR201303001

16. Lu C, Hansen E, Sapozhnikova A, Hu D, Miclau T, Marcucio RS. Effect of age on vascularization during fracture repair. J Orthop Res (2008) 26(10):1384-9. doi:10.1002/jor.20667

17. Griffith JF, Wang YX, Zhou H, Kwong WH, Wong WT, Sun YL, et al. Reduced bone perfusion in osteoporosis: likely causes in an ovariectomy rat model. Radiology (2010) 254(3):739-46. doi:10.1148/radiol.09090608

18. Schalkwijk CG, Stehouwer CD. Vascular complications in diabetes mellitus: the role of endothelial dysfunction. Clin Sci (2005) 109(2):143-59. doi:10.1042/ CS20050025

19. Okerson T, Chilton RJ. The cardiovascular effects of GLP-1 receptor agonists. Cardiovasc Ther (2012) 30(3):e146-55. doi:10.1111/j.1755-5922.2010.00256.x

20. Nystrom T, Gutniak MK, Zhang Q, Zhang F, Holst JJ, Ahren B, et al. Effects of glucagon-like peptide- 1 on endothelial function in type 2 diabetes patients with stable coronary artery disease. Am J Physiol Endocrinol Metab (2004) 287(6):E1209-15. doi:10.1152/ajpendo.00237.2004

21. Ban K, Noyan-Ashraf MH, Hoefer J, Bolz SS, Drucker DJ, Husain M. Cardioprotective and vasodilatory actions of glucagon-like peptide 1 receptor are mediated through both glucagon-like peptide 1 receptor-dependent and -independent pathways. Circulation (2008) 117(18):2340-50. doi:10.1161/ CIRCULATIONAHA.107.739938

22. Williams GA, Callon KE, Watson M, Costa JL, Ding Y, Dickinson M, et al. Skeletal phenotype of the leptin receptor-deficient $\mathrm{db} / \mathrm{db}$ mouse. J Bone Miner Res (2011) 26(8):1698-709. doi:10.1002/jbmr.367

23. Orland MJ, Permutt MA. Quantitative analysis of pancreatic proinsulin mRNA in genetically diabetic (db/db) mice. Diabetes (1987) 36(3):341-7. doi:10.2337/diab.36.3.341

24. Ealey KN, Fonseca D, Archer MC, Ward WE. Bone abnormalities in adolescent leptin-deficient mice. Regul Pept (2006) 136(1-3):9-13. doi:10.1016/j. regpep.2006.04.013

25. Mansur SA, Mieczkowska A, Flatt PR, Bouvard B, Chappard D, Irwin N, et al. A new stable GIP-oxyntomodulin hybrid peptide improved bone strength both at the organ and tissue levels in genetically-inherited type 2 diabetes mellitus. Bone (2016) 87:102-13. doi:10.1016/j.bone.2016.04.001

26. Vijan S. In the clinic. Type 2 diabetes. Ann Intern Med (2010) 152(5):ITC31-15. doi:10.7326/0003-4819-152-5-201003020-01003

27. Roche B, Vanden-Bossche A, Normand M, Malaval L, Vico L, Lafage-Proust MH. Validated laser Doppler protocol for measurement of mouse bone blood perfusion-response to age or ovariectomy differs with genetic background. Bone (2013) 55(2):418-26. doi:10.1016/j.bone.2013.03.022

28. Bouxsein ML, Boyd SK, Christiansen BA, Guldberg RE, Jepsen KJ, Muller R. Guidelines for assessment of bone microstructure in rodents using micro-computed tomography. J Bone Miner Res (2010) 25(7):1468-86. doi:10.1002/jbmr.141

29. Dempster DW, Compston JE, Drezner MK, Glorieux FH, Kanis JA, Malluche $\mathrm{H}$, et al. Standardized nomenclature, symbols, and units for bone histomorphometry: a 2012 update of the report of the ASBMR Histomorphometry Nomenclature Committee. J Bone Miner Res (2013) 28(1):2-17. doi:10.1002/jbmr.1805

30. Mabilleau G, Mieczkowska A, Irwin N, Simon Y, Audran M, Flatt PR, et al. Beneficial effects of a $N$-terminally modified GIP agonist on tissue-level bone material properties. Bone (2014) 63:61-8. doi:10.1016/j.bone.2014.02.013

31. Paschalis EP, DiCarlo E, Betts F, Sherman P, Mendelsohn R, Boskey AL. FTIR microspectroscopic analysis of human osteonal bone. Calcif Tissue Int (1996) 59(6):480-7. doi:10.1007/BF00369214

32. Orriss IR, Taylor SE, Arnett TR. Rat osteoblast cultures. Methods Mol Biol (2012) 816:31-41. doi:10.1007/978-1-61779-415-5_3

33. Odgaard A. Three-dimensional methods for quantification of cancellous bone architecture. Bone (1997) 20(4):315-28. doi:10.1016/S8756-3282(97)00007-0
34. Friedman JM, Halaas JL. Leptin and the regulation of body weight in mammals. Nature (1998) 395(6704):763-70. doi:10.1038/27376

35. Eckel RH, Kahn SE, Ferrannini E, Goldfine AB, Nathan DM, Schwartz MW, et al. Obesity and type 2 diabetes: what can be unified and what needs to be individualized? Diabetes Care (2011) 34(6):1424-30. doi:10.2337/dc11-0447

36. Hamilton BS, Paglia D, Kwan AY, Deitel M. Increased obese mRNA expression in omental fat cells from massively obese humans. Nat Med (1995) 1(9):953-6. doi:10.1038/nm0995-953

37. Chen H, Charlat O, Tartaglia LA, Woolf EA, Weng X, Ellis SJ, et al. Evidence that the diabetes gene encodes the leptin receptor: identification of a mutation in the leptin receptor gene in $\mathrm{db} / \mathrm{db}$ mice. Cell (1996) 84(3):491-5. doi:10.1016/ S0092-8674(00)81294-5

38. Tartaglia LA, Dembski M, Weng X, Deng N, Culpepper J, Devos R, et al. Identification and expression cloning of a leptin receptor, OB-R. Cell (1995) 83(7):1263-71. doi:10.1016/0092-8674(95)90151-5

39. Coleman DL. Obese and diabetes: two mutant genes causing diabetes-obesity syndromes in mice. Diabetologia (1978) 14(3):141-8. doi:10.1007/BF00429772

40. Flatt PR, Bailey CJ, Kwasowski P, Swanston-Flatt SK, Marks V. Abnormalities of GIP in spontaneous syndromes of obesity and diabetes in mice. Diabetes (1983) 32(5):433-5. doi:10.2337/diabetes.32.5.433

41. Scheller EL, Song J, Dishowitz MI, Soki FN, Hankenson KD, Krebsbach PH. Leptin functions peripherally to regulate differentiation of mesenchymal progenitor cells. Stem Cells (2010) 28(6):1071-80. doi:10.1002/stem.432

42. Upadhyay J, Farr OM, Mantzoros CS. The role of leptin in regulating bone metabolism. Metabolism (2015) 64(1):105-13. doi:10.1016/j.metabol.2014.10.021

43. Brunton S, Davidson JA. Exenatide once weekly: a review of pharmacology and treatment considerations in type 2 diabetes. Clin Ther (2016) 38(3):582-94. doi:10.1016/j.clinthera.2016.01.014

44. van Bloemendaal L, RG IJ, Ten Kulve JS, Barkhof F, Konrad RJ, Drent ML, et al. GLP-1 receptor activation modulates appetite- and reward-related brain areas in humans. Diabetes (2014) 63(12):4186-96. doi:10.2337/db14-0849

45. Roszer T, Jozsa T, Kiss-Toth ED, De Clerck N, Balogh L. Leptin receptor deficient diabetic $(\mathrm{db} / \mathrm{db})$ mice are compromised in postnatal bone regeneration. Cell Tissue Res (2014) 356(1):195-206. doi:10.1007/s00441-013-1768-6

46. Lee HM, Joo BS, Lee CH, Kim HY, Ock JH, Lee YS. Effect of glucagon-like peptide- 1 on the differentiation of adipose-derived stem cells into osteoblasts and adipocytes. JMenopausal Med (2015) 21(2):93-103. doi:10.6118/ jmm.2015.21.2.93

47. Balint E, Szabo P, Marshall CF, Sprague SM. Glucose-induced inhibition of in vitro bone mineralization. Bone (2001) 28(1):21-8. doi:10.1016/ S8756-3282(00)00426-9

48. Pereira M, Gohin S, Lund N, Hvid A, Smitham PJ, Oddy MJ, et al. Sclerostin does not play a major role in the pathogenesis of skeletal complications in type 2 diabetes mellitus. Osteoporos Int (2017) 28(1):309-20. doi:10.1007/ s00198-016-3718-0

49. Wu X, Li S, Xue P, Li Y. Liraglutide, a glucagon-like peptide-1 receptor agonist, facilitates osteogenic proliferation and differentiation in MC3T3-E1 cells through phosphoinositide 3-kinase (PI3K)/protein kinase B (AKT), extracellular signal-related kinase (ERK)1/2, and cAMP/protein kinase A (PKA) signaling pathways involving beta-catenin. Exp Cell Res (2017) 360(2):281-91. doi:10.1016/j.yexcr.2017.09.018

50. Feng Y, Su L, Zhong X, Guohong W, Xiao H, Li Y, et al. Exendin-4 promotes proliferation and differentiation of MC3T3-E1 osteoblasts by MAPKs activation. J Mol Endocrinol (2016) 56(3):189-99. doi:10.1530/JME-15-0264

51. Nuche-Berenguer B, Portal-Nunez S, Moreno P, Gonzalez N, Acitores A, Lopez-Herradon A, et al. Presence of a functional receptor for GLP-1 in osteoblastic cells, independent of the cAMP-linked GLP-1 receptor. J Cell Physiol (2010) 225(2):585-92. doi:10.1002/jcp.22243

52. Hu XK, Yin XH, Zhang HQ, Guo CF, Tang MX. Liraglutide attenuates the osteoblastic differentiation of MC3T3E1 cells by modulating AMPK/mTOR signaling. Mol Med Rep (2016) 14(4):3662-8. doi:10.3892/mmr.2016.5729

53. Aoyama E, Watari I, Podyma-Inoue KA, Yanagishita M, Ono T. Expression of glucagon-like peptide-1 receptor and glucose-dependent insulinotropic polypeptide receptor is regulated by the glucose concentration in mouse osteoblastic MC3T3-E1 cells. Int J Mol Med (2014) 34(2):475-82. doi:10.3892/ ijmm.2014.1787

54. Andreozzi F, Raciti GA, Nigro C, Mannino GC, Procopio T, Davalli AM, et al. The GLP-1 receptor agonists exenatide and liraglutide activate glucose 
transport by an AMPK-dependent mechanism. J Transl Med (2016) 14(1):229. doi:10.1186/s12967-016-0985-7

55. Beckman JA, Creager MA, Libby P. Diabetes and atherosclerosis: epidemiology, pathophysiology, and management. JAMA (2002) 287(19):2570-81. doi:10.1001/jama.287.19.2570

56. Anetzberger H, Thein E, Becker M, Zwissler B, Messmer K. Microspheres accurately predict regional bone blood flow. Clin Orthop Relat Res (2004) 424:253-65. doi:10.1097/01.blo.0000128281.67589.b4

57. Shymkiw RC, Zernicke RF, Forrester KR, Bray RC. Evaluation of laser-Doppler perfusion imaging for measurement of blood flow in cortical bone. J Appl Physiol (2001) 90(4):1314-8.

58. Stabley JN, Prisby RD, Behnke BJ, Delp MD. Type 2 diabetes alters bone and marrow blood flow and vascular control mechanisms in the ZDF rat. $J$ Endocrinol (2015) 225(1):47-58. doi:10.1530/JOE-14-0514

59. Nystrom T, Gonon AT, Sjoholm A, Pernow J. Glucagon-like peptide-1 relaxes rat conduit arteries via an endothelium-independent mechanism. Regul Pept (2005) 125(1-3):173-7. doi:10.1016/j.regpep.2004.08.024

60. Selley E, Kun S, Szijarto IA, Laczy B, Kovacs T, Fulop F, et al. Exenatide induces aortic vasodilation increasing hydrogen sulphide, carbon monoxide and nitric oxide production. Cardiovasc Diabetol (2014) 13:69. doi:10.1186/1475-2840-13-69

61. Smits MM, Muskiet MH, Tonneijck L, Kramer MH, Diamant M, van Raalte DH, et al. GLP-1 receptor agonist exenatide increases capillary perfusion independent of nitric oxide in healthy overweight men. Arterioscler Thromb Vasc Biol (2015) 35(6):1538-43. doi:10.1161/ATVBAHA.115.305447

62. Prisby R, Guignandon A, Vanden-Bossche A, Mac-Way F, Linossier MT, Thomas $\mathrm{M}$, et al. Intermittent PTH(1-84) is osteoanabolic but not osteoangiogenic and relocates bone marrow blood vessels closer to bone-forming sites. J Bone Miner Res (2011) 26(11):2583-96. doi:10.1002/jbmr.459

63. Griffith JF, Yeung DK, Tsang PH, Choi KC, Kwok TC, Ahuja AT, et al. Compromised bone marrow perfusion in osteoporosis. J Bone Miner Res (2008) 23(7):1068-75. doi:10.1359/jbmr.080233

64. Anichini R, Cosimi S, Di Carlo A, Orsini P, De Bellis A, Seghieri G, et al. Gender difference in response predictors after 1-year exenatide therapy twice daily in type 2 diabetic patients: a real world experience. Diabetes Metab Syndr Obes (2013) 6:123-9. doi:10.2147/DMSO.S42729

65. Richard JE, Anderberg RH, Lopez-Ferreras L, Olandersson K, Skibicka KP. Sex and estrogens alter the action of glucagon-like peptide-1 on reward. Biol Sex Differ (2016) 7:6. doi:10.1186/s13293-016-0059-9

Conflict of Interest Statement: The authors declare that the research was conducted in the absence of any commercial or financial relationships that could be construed as a potential conflict of interest.

AF was employed by the company Transpharmation but did not provide any funding.

Copyright (C) 2017 Pereira, Gohin, Roux, Fisher, Cleasby, Mabilleau and Chenu. This is an open-access article distributed under the terms of the Creative Commons Attribution License (CC BY). The use, distribution or reproduction in other forums is permitted, provided the original author(s) or licensor are credited and that the original publication in this journal is cited, in accordance with accepted academic practice. No use, distribution or reproduction is permitted which does not comply with these terms. 